
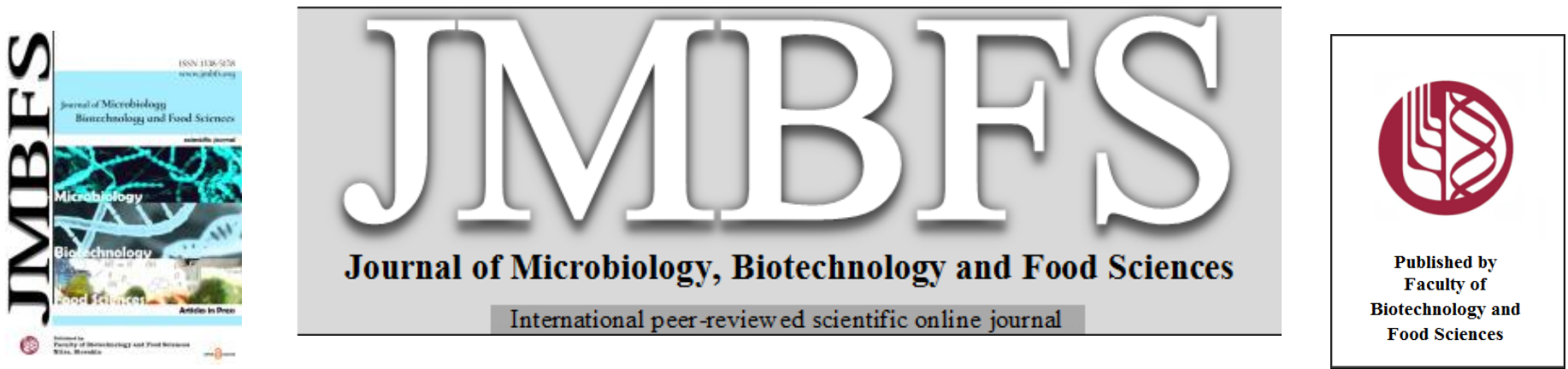

\title{
CURRENT USE OF NANOPROTEIN AND APPLICATION IN THE DEVELOPMENT OF FOOD PRODUCTS FOR FUNCTIONAL AND NUTRITIONAL BENEFITS
}

\author{
Shalini Biswas ${ }^{1}$, Samadrita Sengupta*2
}

\section{Address(es): Dr. Samadrita Sengpta,}

${ }^{1}$ West Bengal State University, Post Graduate Student, Department of Food and Nutrition, Berunanpukhuria, Barasat, Kolkata-126, West Bengal, India.

${ }^{2}$ West Bengal State University, Assistant Professor, Department of Food and Nutrition, Berunanpukhuria, Barasat, Kolkata-126, West Bengal, India, (+91)9903780850.

*Corresponding author: senguptasamadrita3625@gmail.com

\section{ARTICLE INFO}

Received 27. 5. 2019

Revised 20.11. 2021

Accepted 8. 12. 2021

Published 1. 4. 2022

Regular article

OPEN $\partial_{\text {ACCESS }}$

\begin{abstract}
In the last few decades, there has been a growing interest in the production of Nano protein particles from food protein. The term Nanotechnology refers to the formation of materials, devices, and systems by manipulating their matter into a length scale of $\sim 1-100 \mathrm{~nm}$. Nanoparticles can be formed from various types of materials like metals, polysaccharides, and proteins. Biological protein-based nanoparticles made from whey, soy, corn zein are advantageous for health and possess relatively low cost. For the production of Nano protein, the physical and chemical properties of proteins can be modified for specific food and make the protein applicable for biotechnological purposes. Specific structure and number of functional groups in protein that are responsible for the physicochemical properties are selectively modified during the preparation of Nano protein. Nano protein particles are used in a wide range of settings and it replaces many particles which are not biocompatible and exerts a negative effect on the environment. In the food industry Nano protein is a revolutionary fact to maintain the color, flavor, and nutritive value of food. Various types of natural and synthetic nanoparticles are available in the food and pharmacological industry but among them, protein-based nanoparticles are widely used because of their size and relatively easy method of preparation. These nanoparticles are used in the loading and delivery of physiologically active compounds like nutraceuticals. Nano protein formation is also helped to combat global food security challenges which are related to the increased global population, unstable world economy, and climate changes.
\end{abstract}

Keywords: Nanoparticle; nanotechnology; nutrition; nutraceutical; functional food

\section{INTRODUCTION}

Protein-based nanoparticles are widely used in the development of functional food Recent nanoparticles show a promising effect in the field of the food industry. Nano protein is widely used due to its high nutritional value, availability, and acceptability. In the current year, food protein is used to prepare nanoparticles which are further used in the formation of the innovative functional food product. The most important fact is to control the size of nanoparticles for determining the taste, flavor, texture, appearance, and rate of release of bioactive compounds in the biological system (Chen et al., 2006).

Nanomaterials permit improved encapsulation and release efficiency of the active food ingredients related to traditional encapsulating agents, and the development of nano-emulsions, liposomes, micelles, and biopolymer complexes have directed to improved properties for bioactive compounds protection, organized delivery systems, food matrix assimilation, and masking undesired flavors. Nanotechnology also has the prospective to improve food processes that use enzymes to confer nutrition and health benefits. Nano protein hydrolysate is easily developed with anti-nutritive components and hence surges the bio-availability of minerals and vitamins. Nanomaterials create a major interest for the development of advanced packaging systems, by improving mechanical and barriers properties of food packages. In the food industry, nanomaterials are used to improve the mechanical strength, electrical conductivity, and thermal stability of food materials (Sharma et al., 2017). Over the next few decades, proteins-based nanomaterials will play a major role in developing the efficacy of functional food. Nanomaterials are also used to stabilize fragile nutraceuticals and the formation of site-specific carrier targeting. At present the more knowledge and information about proteinprotein and protein-nutraceutical interaction is required to develop the design of nutraceuticals carriers for use in the food industry (Chen et al., 2006).

\section{Nano protein in food processing}

In recent few decades' nanotechnologies and nanoscience implies a new and innovative application in the food industry. The term Nanotechnology refers to the formation of materials, devices, and systems by manipulating their matter into a length scale of $\sim 1-100 \mathrm{~nm}$. Nanotechnology has been considered a most attractive and revolutionary method in the food sector. Nanotechnology offers a wide range of advantages in food processing technology, food packaging material, and the formation of nanomaterials for use in foods without affecting nutritive value and protection from adverse health effects. Nanotechnology is also applied for the improvement of tastes, color, and texture, consistency of foodstuff, increased bioavailability, and absorption of food material. The application of nanotechnology is new in the food sector but, predictably, this technology is growing rapidly in the coming years (Srinivas et al., 2010; Chaudhary et al., 2008; Singh et al., 2017)

Nowadays Nanocarriers are used as a delivery agent to deliver active food components and food additives in food. In the food industry nanotechnology is applied for the formation of emulsion, encapsulation, simple solution, and association colloids which offers efficient delivery systems (Singh et al., 2017) Nano emulsion is widely used to encapsulate various lipophilic components, such as lycopene, lutein, capsaicin, astaxanthin, beta-carotene, lemon oil, D-limonene, vitamin E, and omega-3 oil. Studies revealed that the incorporation of coenzyme Q 10 into nano emulsion increases the bioavailability of coenzyme. Antiinflammatory activity, stability, and oral bioavailability of polyphenols of curcumin and epigallocatechin gallate are enhanced by incorporation into nanoemulsion. The bioavailability of heptadecanoic acid is increased when it is encapsulated indigestible oil droplets with the smallest size (Yalcmoz et al., 2018). Nano emulsion is used to formulate smart food in the food industry for example nano emulsion is prepared with beta-carotene. Beta-carotene is a water-soluble pigment and has an effective health benefit. This emulsion is stabilized by $\beta$ lactoglobulin which is a biocompatible emulsifier. The bioavailability of these emulsions is high (Gupta, 2016).

Nanoencapsulation is one of the most effective parts of the food processing industry in which solid, liquid, and gaseous materials are packed into different carriers such as capsules. Many nutraceuticals, functional food components including protein, vitamins, fat, and minerals are encapsulated in a perfect delivery system and exert their functional properties. Nanoencapsulation of the bioactive peptide is a most challenging concept and this process increased the bioavailability of bioactive peptides by using a nano delivery system. Many bioactive ingredients are prone to react with other food and loss their bioavailability, as a result, the encapsulation process is very helpful to protect bioactive components without 
affecting their functional properties, color, and flavor (Burcu et al., 2014; Mohan et al., 2015). The food industry also continues its investigation with this technology to face the growing demand for the functional ingredient of food (Mohan et al., 2015).

\section{Nano protein in food preservation and shelf life}

Many bioactive ingredients are prone to react with other food and loss their bioavailability as a result nanoencapsulation is very helpful to protect the bioactive component from degradation without affecting their functional properties, color, and flavor (Burcu et al., 2014). Edible nano-coatings on various food material are effective because they hinder the exchange of moisture and gas and retain color, antioxidants, enzymes, anti-browning agent. This technology helps to increase the shelf life of manufactured food even after the opening of the packet. Encapsulation of functional components slows down the chemical degradation process by modifying the properties of the interfacial layer which are surrounding them Curcumin is a bioactive compound of turmeric and least stable in norma conditions. The stability of curcumin is increased by pasteurization and at different ionic strengths upon encapsulation (Singh et al., 2018). Microorganisms are the leading cause of food spoilage. The addition of antimicrobial agents in food packaging material prevents the growth of microbes and increases the shelf life of food. When antimicrobial agents are incorporated into the packaging film, they can be dispersed onto the food surface through migration, evaporation, or diffusion abilities. Recently a bio-nano composite film has been developed from fish skin gelatin and silver-copper bimetallic nanoparticle. This biofilm is active against the growth of Listeria monocytogenes and Salmonella enteric.

In recent years, an intelligent type of nano-coating film has been developed by few researchers which can indicate the presence of any contamination in food materia that has occurred during storage. Other methods such as Gas content and noninvasive detection methods exert the great ability to detect and monitor the gas content, excess moisture, and oxygen content of a package-headspace. Thus, biofilm provides an effective measure to evaluate the quality and safety of food even after the production process has been done. The presence of oxygen inside the packaging can cause shelf-life threatening of food due to the ability of oxygen to create a healthy environment for microbial growth (Bajpai et al., 2018).

\section{Nano protein in food packaging}

Now day's global food industry deals with consumer demand for safe, healthy, and fresh food. Besides this, they have to meet the condition of food safety regulations. To supply safe food products, foods manufacturers, traders, and food regulatory authorities are looking for a novel, cost-effective, fast, and consistent measure. The application of nanotechnology in food packaging brings three major possibilities and those are direct incorporation into food products, incorporation in food packaging material, and application in food processing (Sharma et al., 2016).

The demand for effective food packaging can be meet by nanomaterial augmented polymers which help to enhance safety and also addressed environmental concerns The packaging material should have to reduce any interaction between food material and packaging, adverse effect on consumer's health and amount of waste materials. Nanocomposites are another conventional technology responsible for improving polymer properties, increased barrier properties, increased material strength, and improved heat resistance. When nanocomposites are used in food packaging, they have shown their ability to withstand the stress of thermal food processing, transport, and storage because their structure is much less permeable to gasses than other materials (Chaudhury et al., 2008; Arora et al., 2010). A low permeability Nanocomposite is produced by blending nano clays with thermoplastics and elastomers for food packaging and consumer products. Nano clay polymer material possesses superior mechanical characteristics. This process is beneficial to reduce the problem of wastage and spoilage of food which occurs due to the exposer of food to atmospheric gasses, moisture, and light for a prolonged period. Antimicrobial packaging has been developed increasingly in the food industry to enhance the quality and shelf-life of the product. In this concern, nano silver composite is used in food packing because of its antimicrobial properties. Silver inhibits the growth and metabolism of bacteria and also comprises a large surface area which provides a barrier against the harmful effect of microorganisms. The use of silver as nanoparticles possesses a less environmentally toxic manufacturing method when it is to be utilized on a commercial scale (Sankaria et al., 2012).

Animal and Vegetable sources of nano protein and their application in the food industry

\section{Soy protein}

Soy proteins are a significant source of food proteins. In the past few decades, soy protein has been used in the formulation of several foods. It is used in a wide spectrum due to its good nutritional value, functionality, acceptability, and availability and it also exerts potential health benefits. Amino acid composition of soy proteins helps to protect against bacterial infection (Peles et al., 2013).

Soy protein isolates are the enriched form of soya protein (SPI). Soy protein isolates possess a balanced composition of nonpolar, polar, and charged amino acids, which can be incorporated into drugs or protein-based delivery system with its all-functional groups. The major components present in SPI are glycinin. These components exist as globular molecules in an aqueous environment and consist of a hydrophilic shell and hydrophobic kernel, which together form water-soluble aggregates. SPI molecules continue to and form structures like microspheres, hydrogels, and polymer blends when dissolvent or crosslinking agents are added. For evaluating the encapsulating property of SPI curcumin was selected as a mode drug. During the commercial production of SPI, the globulins in SPI are easily denatured, as a result, most of the globulin is found in aggregated form. Aggregated proteins in SPI exhibit good surface-active properties due to their insoluble nature This protein helps in the formation of effective Pickering and Pickering stabilizers (Liu et al., 2013; Brandenbur et al., 1993).

Soy protein is easily digested and biodegradable. Soy protein isolate (SPN) of defeated soy flour is used for soya protein nanoparticle (SPNs)production. Soy yogurt developed from SPNs and rice bran oil is considered a functional food product because of its valuable physiological functions (Sengupta, Goswami, Basu and Bhowal, 2019; Sengupta, Bhattacharyya, and Bhowal, 2018; Sengupta, Koley, Dutta, and Bhowal, 2019a; Sengupta, Koley, Dutta, and Bhowal, 2019b). Soy protein is used in tissue engineering for wound healing and transdermal drug delivery in the form of films, scaffolds, and hydrogels (Tansaz, 2016).

\section{Corn zein}

Cornzein is present within the cytoplasm of corn cell endosperm. It has a low molecular weight $(20 \mathrm{kDa})$. Corn zein is insoluble in water and becomes soluble in the presence of alcohol, urea, alkali, and anionic detergents. The structure of zein is helical wheel-shaped with nine homologous units arranged in a parallel way with hydrogen bonds. This helical shape provides a globular structure to corn zein which makes it similar to insulin and ribonuclease (DeFrates et al., 2018). The nanoparticle of zein has been used as carriers of non-polar drugs as it protects encapsulated components from the acidic environment of the stomach. Zeinnano particles improved their properties by combining the natural polymer with other substances. Sodium caseinate is incorporated with zein nanoparticles to improve the stability of particles in water (Defrates et al., 2018; Anderson and Lamsal, 2011). Zein is commonly used in chewing gum and as a preservative coating for some food and pharmaceutical products. Corn zein nanoparticle is useful for controlled release of fat components such as alpha-tocopherol (Anderson and Lamsal, 2011).

\section{Whey protein}

Milk protein is an important source of whey. Whey protein constituent approx $20 \%$ milk protein. Beta-lactoglobulin, alpha -lacto albumin, serum albumin, immunoglobulin are the most important whey protein. These biologically active peptide fractions can be obtained from hydrolysis and used in the production of functional food (Kinsella et al., 1989). Bioactive peptides are inactivated in the parent protein molecule and can be activated by hydrolysis of the protein molecule. There are different types of hydrolysis procedures but the most common procedure is enzymatic degradation for the production of bioactive peptides. The hydrolysis process is beneficial as it retains nutritional properties unaffected. Hydrolysate's enzymes improved stability at heat treatment, provide peptides specific for special diet and improve functional properties such as gelation, foaming, and emulsifying capacity. Various treatments including heating, high pressure, sulfidation, changing the polarity of the environment make the protein susceptible to hydrolysis. Physic-chemical changes occur due to physical and chemical treatment which influence the state and stability of the native protein (Burcu et al., 2014; Schmidt and Markwijk, 1993). Hydrolysed whey protein-based formulas are beneficial for children. Proteins are broken down into peptides and free amino acids during hydrolysis. Through this hydrolysis process formulation of the biologically active nutritional component from whey protein provides healthpromoting opportunities for the use of dairy ingredients. Manipulation of molecular size of biologically active peptides is an essential step in the development of protein hydrolysate for dietary use. (Burcu et al., 2014).

\section{The technology of production of nano protein from the different protein-rich source material}

In recent years Plant protein-based nano-delivery systems are gaining attention in the food industries because of consumer demand for vegetable diets. To improve the functional properties of plant proteins several physical and chemical methods are required. Soy protein nano-aggregates have been produced by using a combined method of $\mathrm{pH}$-shifting and mano-thermo-sonication (MTS). In this method, Soy-protein, isolate (SPI) is treated with $\mathrm{pH}$-shifting at $\mathrm{pH} 12$ or in combination with MTS and high-pressure homogenization (HPH). The resulted from SPI aggregates are spherical with the smallest size, $27.1 \pm 1 \mathrm{~nm}$. Soy protein nano-aggregates have improved properties of highest protein solubility, lowest turbidity, free sulfhydryl and disulphide bonds, surface hydrophobicity, antioxidant activity, and rheological and emulsifying properties than the other samples (. The SPI nano aggregates have good stabilizing power as a result these 
are used to prepare oil-in-water nano emulsions with canola oil and provide stability over 21 days at $4{ }^{\circ} \mathrm{C}$ (Yildiz et al., 2017).

Zhang et al., (2014) has been developed a study to investigate the influences of nano-bacterial cellulose (Nano-BC)/soy protein isolate (SPI) complex gel on the textural, rheological, and sensory properties of the ice cream model. Nanobacterial cellulose (Nano-BC)/soy protein isolates (SPI) mixtures with different ratios (Nano-BC: SPI, 1:20, 1:15, 1:10, and 1:5 w/w) are prepared with constant total solid content $(16 \%)$. The result showed that the thermal stability, textural, rheological, and emulsifying properties of nano-BC/SPI mixtures are improved than pure SPI. Some properties such as low calorie, melting resistance, and good textural properties of ice cream are developed When $20 \%$ of nano-BC/SPI (1:20) mixture was added into ice cream as the cream substitute (Guo et al., 2018).

Nanoparticles are produced from soy protein by using dispersion, disolvation, drug incorporation, cross-linking, and evaporation process. Particle size, size distribution, and zeta potential play important role in the production of nanoparticles. Curcumin is used as model drug and encapsulated in into nanoparticles. In this process, the average size of the curcumin loaded nanoparticles was 220.1 to $286.7 \mathrm{~nm}$, and their zeta potential was around $-36 \mathrm{mV}$ (Teng et al., 2012).

lutein loaded nano-emulsions are produced by using whey protein isolate (WPI) or polymerized whey protein isolate (PWP) with the help of a high-intensity ultrasound method. Lutein is a hydrophobic carotenoid that has various health functions but due to its poor solubility in water and instability under certain conditions during storage the application of lutein is limited. The lutein loaded WPI based nano-emulsion system showed stable physiochemical stability during the storage at $4^{\circ} \mathrm{C}$ and the lutein content of the system was reduced by only $4 \%$ after four weeks of storage at $4^{\circ} \mathrm{C}$ (Zhao et al., 2018).

Nano emulsions have significant use in the food industry. Nano emulsion preparation methods include low-energy and high-energy methods. Low energy method used to prepare oil/water nano emulsion. Commonly used low energy techniques are phase inversion temperature (PIT), phase inversion composition (PIC), and spontaneous emulsion (SE). High-energy methods are the most appropriate for the preparation of nano emulsions in food industries because of the utilization of non-toxic/natural emulsifiers at lower concentration levels. High energy methods are mechanical procedures where mechanical equipment is used to separate the dispersed phase into droplets inside the continuous phase and generate highly disruptive forces. high-energy methods include rotor-stator emulsification (RSE), high-pressure homogenization (HPH), high-pressure microfluidic homogenization (HPMH), and ultrasonic homogenization (USH) (Liu et al., 2019). Different method of nano protein production from various protein source is shown on Tab $\mathbf{1}$

Table 1 Different Method of Nano protein Production

\begin{tabular}{|c|c|c|c|}
\hline$x^{2+2}$ & Materials & Use & Citation \\
\hline $\begin{array}{l}\text { pH-shifting and nano-thermo- } \\
\text { sonication (MTS) }\end{array}$ & Soy protein & $\begin{array}{c}\text { Oil-in-water nano emulsion } \\
\text { with canola oil }\end{array}$ & (Gulcin et al., 2017) \\
\hline $\begin{array}{l}\text { Nano-BC: SPI, 1:20, 1:15, 1:10, and } \\
1: 5 \mathrm{w} / \mathrm{w}\end{array}$ & $\begin{array}{c}\text { Nano-bacterial cellulose/soy } \\
\text { protein isolate }\end{array}$ & $\begin{array}{c}\text { ice cream as the cream } \\
\text { substitute }\end{array}$ & (Zhang et al., 2018) \\
\hline high-throughput encapsulation & whey and soy protein hydrogels & bioactive delivery systems & (Echegoyen et al., 2016) \\
\hline $\begin{array}{l}\text { Dispersion, desolvation, drug } \\
\text { incorporation, cross-linking, and } \\
\text { evaporation }\end{array}$ & Soy protein & $\begin{array}{l}\text { Nutraceutical } \\
\text { Encapsulation }\end{array}$ & (Teng et al., 2012) \\
\hline Nano encapsulated & $\begin{array}{c}\text { pectin-whey protein nano- } \\
\text { complexes }\end{array}$ & carriers of orange peel oil & (Ghasemi, 2017). \\
\hline High intensity ultrasound & $\begin{array}{c}\text { lutein encapsulated whey } \\
\text { protein } \\
\text { nano-emulsion }\end{array}$ & $\begin{array}{c}\text { food and beverage } \\
\text { industries and dietary } \\
\text { supplements }\end{array}$ & (Zhao, 2018) \\
\hline $\begin{array}{l}\text { Nanoparticle protein corona (NP- } \\
\text { PC) by gel electrophoresis. } \\
\text { Chemical fabrication of the NP } \\
\text { surface by polyethylene glycol }\end{array}$ & Nanoparticles and protein & $\begin{array}{l}\text { Modify transfer of protein, } \\
\text { promote translocation of } \\
\text { NP across cellular barriers. }\end{array}$ & (Saptarshi, 2013) \\
\hline $\begin{array}{l}\text { Novel polyphenol encapsulation by } \\
\text { high speed and high pressure } \\
\text { homogenized oil-in-water emulsion. }\end{array}$ & $\begin{array}{c}\text { Water insoluble compound of } \\
\text { curcumin. } \\
\text { Dibenzo methane. }\end{array}$ & Anti-inflammatory activity & (Huang et al., 2008) \\
\hline $\begin{array}{l}\text { Nano emulsion. High energy and } \\
\text { low energy approaches }\end{array}$ & $\begin{array}{l}\text { Solvents- n-hexene, sunflower } \\
\text { oil, MCTs. } \\
\text { Emulsifiers- lipids, flavors, } \\
\text { antioxidant, antimicrobial drugs. }\end{array}$ & $\begin{array}{l}\text { Improve bioavailability and } \\
\text { stability of active } \\
\text { compound. }\end{array}$ & (Silva et al., 2012) \\
\hline
\end{tabular}

\section{Sensory properties of nano protein-based food product}

In recent years Nanotechnology is widely used to improve the functiona properties, taste, flavor, texture, and shelf life of food products by modifying thei physical, chemical, and biological properties. Ingredients in food products that are subjected to form nanostructure increase the bioavailability of nutrients and improve the sensory properties of food (Singh et al., 2016). Chitosan is a useful nutrient and has microbial activity, protective film formation ability, binding action, and antioxidant activity. Chitosan nanoparticles are used as an edible coating material for fishery products such as fish fingers, fish balls, etc. to increase the microbiological quality and shelf life of fish products. Chitosan nanoparticle coating prevents lipid oxidation on the fish finger and enhances the shelf life of fish products during storage conditions (Abdou et al., 2012).

Food grade nanoparticles have been used to stabilize novel Pickering emulsions, due to their compatibility with food and good stabilizing power concerning coalescence. These types of emulsions imply good functional performance that can be used as an effective delivery system and development of novel functional food Soy protein nanoparticles are used as Pickering stabilizers due to their functional, nutritional properties, and availability. The emulsion prepared with Soy protein nanoparticles achieved steric stabilization (Liu and Tang, 2013).

Nanoliposome is produced by applying high energy to phospholipid in an aqueous solution and used in the food industry as a delivery system. Ingredient encapsulated by nanoliposomes are protected from chemical and environmental factors, enzymatic changes, unwanted odor, or taste. Like nano emulsion Nanoliposome increases the stability, and ionic strength of food products. Nanoliposome is mainly used as a colloidal delivery system to deliver hydrophobic bioactive and functional agents. Nanoliposome is produced by inputting high energy to phospholipid in an aqueous solution and used in the food industry as a delivery system. Ingredients encapsulated by nanoliposomes are protected from chemical and environmental factors, enzymatic changes, unwanted odor, or taste.
Like nano emulsion, nanoliposomes increases the stability, and ionic strength of food products. Nanoliposome is mainly used as a colloidal delivery system to deliver hydrophobic bioactive and functional agents (Meghani et al., 2019).

When resveratrol was encapsulated in soy protein Isolates exhibited higher solubility, stability, and bioactive properties compared to free resveratrol. the SP nanoparticles are developed by using the rotary evaporation technique and the size of nanoparticles was approximately 100nm (Martins et al., 2018).

Barley protein nanoparticles (90-150nm) are used to load $\beta$-carotene because of its high loading capacity and excellent stability. Barley nanoparticles are produced by the method of high-pressure homogenization without using any surfactants or organic solvents (Yang et al., 2015). Titanium dioxide and silicon dioxide $\left(\mathrm{SiO}_{2}\right)$ nanomaterials have been used to protect the color and flow of food items. $\mathrm{SiO}$ nanomaterials are commonly used food-based nanomaterials and act as carriers of fragrances or flavors in food products (Dekkers et al., 2011)

\section{Correlations between the properties of different crystal ranges of} nanoparticle and their suitability in food applications

No single technique can provide information about the properties of differen crystal ranges of nanoparticles as result different types of analytical methods are required to determine the size distribution and properties of nanoparticles. Analytical tools used are ranging from electron microscopy to dynamic ligh scattering to field-flow fractionation techniques. Particle size affects the texture of nanoparticles. Small particle size is desirable than large particles for nanoencapsulation of bioactive compounds as they can be easily included in the food matrix. An investigation has shown that nano emulsions with small droplet sizes are more stable against aggregation, flocculation, and coalescence compare to microemulsions. Nano emulsions are widely used in the food industry to encapsulate bioactive products because nano emulsion droplets easily break and distribute bioactive components in the GI tract. Immunoglobulin G has been 
encapsulated in soya protein-based nano emulsion and is stable against $\mathrm{pH}-2.0$ and $\mathrm{pH}-12.0$. Lactoferrin which is an antimicrobial component of whey protein when encapsulated in liposome nanoparticles is more stable at $37^{\circ} \mathrm{C}$ for $4 \mathrm{~h}$ in the stomach (Cabuk et al., 2014).

In the food industry, the demands and applications of nanomaterials are higher than microscale materials. Nanomaterials are more suitable to develop food products because of their higher exposure per unit mass, different routes of exposure, wide distribution to tissue due to their small size. Another important property of nanoscale material is that it can alter absorption, digestion, metabolism, or excretion in the body (Srinivas et al., 2010).

Correlations between various physical properties, antioxidant activity, and crystal size of the nanoparticle

Antioxidant molecules interact with free radicals, prevent chain reactions and protect the human body from the harmful effect of oxidative stress (Lobo et al. 2010). Antioxidants may be obtained from endogenous sources such as glutathione or exogenous sources, which are generally present in our diet. Recently nanomaterials antioxidant and nano encapsulated antioxidant have been developed from inorganics or biological sources. Melanin nanoparticles act as a potential antioxidant (Liu et al., 2017). Au, Ag, Pt are used to develop metal nanoparticles due to their antioxidant activity (Yusof and Ismail, 2015). Nanoparticles protect antioxidants from environmental factors, increase the bioavailability of antioxidants and deliver them to the target site. An antioxidant can be formed from redox inactive nanomaterial by grafting low molecular weight antioxidants on them. Natural antioxidant conjugated with nanoparticles has shown increase chemical stability, intact molecular form, slow and continuous release of bioactive component (Chakraborty and Jana, 2017). The antioxidant activity of gallic acid remains intact when it is encapsulated into zein nanofibers. Zein nanofibers are produced by using the electrospinning method (Martins et al., 2018). Another study investigated the reactive oxygen species (ROS) generating capacity of $\mathrm{TiO} 2$ nanoparticles with varying crystal sizes but the same crystal phase. The result has been shown that the highest ROS generation per unit area occurs for $30 \mathrm{~nm}$ particles and it is constant above $30 \mathrm{~nm}$. The ROS generating activity was decreased as the crystal size decreased from $30 \mathrm{~nm}-10 \mathrm{~nm}$ and constant for $10 \mathrm{~nm}$ particle size (Jiang et al., 2008).

\section{Nutritional properties of nanoparticles concerning crystal size and physiological problem.}

Nanoparticles act as a vehicle to deliver the nutritional and bioactive compound to the target cell, the main aim of this method is to improve Nutrition, health and reduce the risk of disease. Nutrients that are used to apply nanotechnology include fat-soluble vitamins eg. A, D, E, water-soluble vitamins c, B12, iron, amino acid, folic acid, zinc, and calcium (Kulkarni et al., 2016). When nutrient or other bioactive compounds are encapsulated in a suitable nanocarrier, they are released after consumption of the food and utilized based on nutritional properties. Structural lipids have been used as carriers of a healthy component to inhibit the transport of cholesterol from the digestive system to the bloodstream. The physical, chemical and biological properties of nanoscale materials differ according to their particle size. In specific cases and where warranted by concerns for the environment, health, safety, or competitiveness the number size distribution threshold of 50\% may be replaced by a threshold between 1 and 50\% (Jampilek et al., 2019).

Soy protein isolates-based nanoparticles has increased intestinal transport (2-3 times) of vitamin B-12 than non-encapsulated vitamin B12. When the nanoparticle size decreased from 180 to $30 \mathrm{~nm}$ vitamin B-12 transport through the cell increased (Zhang et al., 2014). $\beta$-lactoglobulin nanoparticles with the size of $142 \mathrm{~nm}$ have higher encapsulation efficiency. Solubility of encapsulated curcumin was increased 6.7 times compared to curcumin alone (Martins et al., 2018).

In the different regions of the GI tract, nanoparticle-based structures experience a series of physiological processes and then get a chance to release bioactive compounds. The beneficial effect of the bioactive compound depends on the preservation of bioavailability after ingestion of food. Several factors like low solubility in gastrointestinal (GI) tract fluids, instability under gut conditions, and low residence time regulate the activity and effectiveness of the bioactive compound. The encapsulation method is advantageous to protect the potential health benefits of bioactive compounds. Epigallocatechin gallate (EGCG) is encapsulated in $\beta$-lactoglobulin nanohydrogels, which act as a protection vehicle in the stomach and release EGCG in a controlled way in the intestine (Shpigelman et al., 2012). When $\beta$-lactoglobulin nanoparticles $(200 \mathrm{~nm}-300 \mathrm{~nm})$ entrapped caffeine, the little release of caffeine (approximately 30\%) was observed at stomach conditions and complete release was achieved at intestinal condition (Guo et al., 2017). Sodium caseinate, whey protein isolate, and soy protein nano complex are used to encapsulate coenzyme-Q10 and the result has shown that increased stability and higher bioavailability of encapsulated coenzyme Q10 (CoQ10) to invitro digestion (Chen et al., 2006). Under gastric condition release of encapsulated b-carotene within soya protein isolate nanoparticle (370 nm diameter) was slow but high release in intestinal condition (Yi et al., 2015).

\section{The physiological effect of nano protein}

Nanoparticles have a unique physiological effect. There is some investigation that revealed the harmful effects of nanomaterials in the in-vitro biological system. But the knowledge to describe the adverse effect of nanoparticles in humans is remaining unclear and it is necessary to understand the molecular mechanism of nanoparticles to biological system interaction. By inhalation, ingestion, or derma penetration Nanoparticles or nanomaterials can enter the body. In the case of food products nanoparticles are mostly exposed to the human body by ingestion. After reaching the biological medium nanoparticles interact with biomolecules such as protein, lipids, and other metabolites due to their nano size and large surface to mass ratio. The two major organs for the distribution of nanoparticles in a biological system are the liver and spleen and then it is passing from the intestine to the circulation. Several studies demonstrate that nanoparticles that are passing through the intestine, eliminated rapidly. Properties of nanomaterials determine the effect of nanomaterials on the human body. In the case of hydrophilic nanoparticles, circulation time is increased and this type of material is positively charged (Dimitrijevic et al., 2015).

\section{Effect on Cardiovascular system}

Several studies have shown that nanoparticles may adversely affect circulation and also affecting microcirculation. Other adverse physiological conditions are damaging of blood vessels when nanoparticles enter into the bloodstream and enhance blood clot formation which may lead to progression of cardiovascular disease. Nano proteins that enter the bloodstream are coated with body proteins. By using the centrifugation procedure four apolipoproteins are converted into model copolymer nano protein particles. These nano proteins are stronger than other plasma proteins with higher abundance (Cedervall et al., 2007).

\section{Effect in liver}

The liver is the major organ where nano proteins are distributed widely. After entering into the biological system nano protein interfere in various biological functions and they can modify the structure of macromolecules. Studies describe the size-dependent toxicity of nanoparticles. The smaller the size is the higher the ability to produce reactive oxygen pieces. These free radicals damage DNA by oxidizing lipids and enhance inflammatory responses. Nano proteins with excessive small diameter accumulate in the liver and continuously affect DNA (Gatoo et al., 2014).

\section{Effect in Respiratory tract}

Studies related to toxicology reported that nano protein with a diameter less than $100 \mathrm{~nm}$ affects respiratory organs. Nanoparticles of different sizes are deposited in the respiratory tract by inhalation. It has been observed that different size of nano protein is distributed differently in various part of the respiratory tract. Ultrafine particle less than $100 \mathrm{~nm}$ is deposited in all regions. Protein with a diameter $<10 \mathrm{~nm}$ is deposited in the tracheobronchial region whereas nano protein with 10-20 diameter deposits in the alveolar. Deposition of nano protein in the respiratory tract for a prolonged period leads to increased translocation to the pulmonary interstitium which enhances the impairment of the function of alveolar macrophage (Gatoo et al., 2014)

\section{Effect in Renal system}

Nano protein is also deposited into renal tissue and they can escape from normal phagocytic defences which lead to toxicity. Gelatine nano protein is also used as an immunological adjuvant to influence cellular response against a foreign antigen. Protein like ovalbumin and serum albumin is used to deliver many therapeutic drugs and endogenous molecules due to its biodegradable, easy synthesis, wellcontrolled size, and easy modification of its functional group on its molecular surface. The other advantage is that drug released from albumin nanoparticles is easily digested by protease enzyme. Albumin carries hydrophobic molecules and reduces the effect of solvent-based toxicity for bodies (Cheng et al., 2016). Several studies have shown that the activity of the bioactive compound is increased when it is in denatured conformation than that of its native state. Conformational changes in protein occur during immobilization and adsorption. This plays a significant role in the design of protein-based nanoparticle. To increase the adsorption of protein on the nanoparticle surface, nanoparticle protein corona (NP-PC) a nanoparticle protein complex is formed. NP-PC influences the activity of protein particles (Cedervall et al., 2007; Saptarshi et al., 2013). Nano emulsion is useful to treat infection of the reticuloendothelial system (RES). It is also applied for enzyme replacement therapy in the liver, treatment of cancer, and vaccination (Jaiswal et al., 2015).

\section{Physicochemical properties of nanoparticles}

Physico-chemical properties are the most important concern for the production of a nanoparticle. The development and effective function of nano protein mostly depend upon $\mathrm{pH}$, size of the particle, and thermal stability. 


\section{$p H$}

Several physical properties of nanomaterials make it suitable to apply in different fields like tribology, surface engineering, nanofabrication, and nonmanufacturing. The electric charge on the surface of nano emulsion plays an important role to stabilize it. Studies reported a negligible influence of $\mathrm{pH}$ on the particle size of nano emulsion. When $\mathrm{pH}$ increases from 7 to 10 the PI value decreases about 0.3 which indicates an effective monodispersity of the nano emulsion. (He et al., 2011 Khan and Saeed, 2017). Nano complex is formed by the electrostatic interaction between components of nano complexes. $\mathrm{pH}$ is an important parameter for the formation of nano complexes by determining the degree of ionization of protein The net charge of the protein is zero at the pi, which leads to $\mathrm{pH}$-related instability of protein nanoparticles. The $\mathrm{pH}$-induced instability of the coacervate nanocomplex is used in drug delivery systems as stimuli-responsive drug released particles. A high protein charge increases the stability of protein micelles and makes the micelles resistant to heat and dehydration (Saptarshi et al., 2013).

\section{Particle size}

Particle size plays a major role in the activity of nanomaterials in biological systems. Generally, the size of nanoparticles ranges from 1-100 nanometres. The size of nanoparticles can vary and it depends upon the molecular weight of the protein-polymer used in the production of the nanoparticle. Nanoparticle size is controlled by preventing the aggregation process. The prevention of aggregation is done by reducing the disulphide bond or by altering the charge of the polymer. Nanoparticle size also depends on the technique which is used to produce those
(Saptarshi et al., 2013). When the size of the nanoparticle is decreased, its surface area is increased and the nanoparticle becomes more active. Studies have been shown that particle size affects various biological systems such as endocytosis, cellular uptake. The pharmacological used size of Nanoparticle determines the behaviour of drugs. Nanoparticles smaller than $50 \mathrm{~nm}$ when administered intravenously, reach rapidly to every tissue and exert a toxic effect in various tissue (Gatoo et al., 2014). Nano emulsions have a droplet size of about $100 \mathrm{~nm}$ Sometimes nano emulsions are transparent in appearance because their droplet size is smaller than the wavelength of visible light. The appearance of nano emulsion 102 is altered by controlling the size of the droplet (Gupta et al., 2016).

\section{Thermal stability}

Nanoparticles have thermal conductivity. Nanofluids exhibit superior properties of thermal stability than those of conventional heat transfer fluid and microscopic size particles present in the fluid. The large total surface area of particles is responsible for increased stability of suspension as heat transfer occurs at the surface of the particle. Studies have been shown that the presence of $\mathrm{CuO}_{2}$ and $\mathrm{Al}_{2} \mathrm{O}_{3}$ in nanofluid increases the thermal conductivity (Khan and Saeed, 2017).

Effect of nano protein in nutrition and food science

Nano protein is widely used in the food industry as the carrier of various bioactive compounds. Nano protein can protect the bioactive compound from degradation and reach the targeted site in the biological system. The application of nano protein in food and nutrition science is shown in Tab 2.

Table 2 Role of Nano protein in Nutrition and Food science

\begin{tabular}{l|c|c|c}
\hline Area & Nano particle & Beneficial effect & Author \\
\hline Macro and micro nutrient & $\begin{array}{c}\text { Encapsulation of protein } \\
\text { vitamin, fat and } \\
\text { antioxidant. }\end{array}$ & $\begin{array}{c}\text { Increase bioavailability, retain } \\
\text { nutritional value, controlled } \\
\text { release of bioactive compound. }\end{array}$ & (Sonkaria, Khare, Ahn, 2012) \\
\hline Probiotic & $\begin{array}{c}\text { Nanoencapsulation of } \\
\text { beneficial microorganism }\end{array}$ & $\begin{array}{c}\text { Functions and properties of } \\
\text { probiotics are not affected, } \\
\text { resistant from degradation. }\end{array}$ & (Chung, 2010) \\
\hline Flavonoids & $\begin{array}{c}\text { Cyanidin 3 O glycoside is } \\
\text { encapsulated within inner } \\
\text { cavity of soybean seeds. }\end{array}$ & $\begin{array}{c}\text { Thermal stability of anthocyanin } \\
\text { is improved. }\end{array}$ & (Zhang et al., 2014) \\
\hline Nutraceuticals & $\begin{array}{c}\text { Encapsulation of rutin with } \\
\text { in homogeneous soybean } \\
\text { seed ferritin. }\end{array}$ & $\begin{array}{c}\text { Protect rutin from UV-radiation } \\
\text { and decrease degradation. }\end{array}$ & (Yang et al., 2015) \\
\hline Metalloxide & $\begin{array}{c}\text { Formation of nano } \\
\text { emulsion by using food } \\
\text { ingredient. }\end{array}$ & $\begin{array}{c}\text { Increased bioavailability, } \\
\text { effective for drug delivery } \\
\text { system. }\end{array}$ & (Remendetto, 2006) \\
\hline
\end{tabular}

\section{Macro and micronutrient}

In the aspect of food and nutrition, nanotechnology confers a wide range of opportunities to improve the quality of the food and enhancement of food taste. Nutritional products produced by using nanotechnology are available in the market. Retention of flavor, color, and nutritive value of food material is the most important concern for the food industry. In this order, nanotechnology is used as a delivery agent to deliver nutritional supplements such as protein, vitamins, fats, and antioxidants. Several biological compounds with low bioavailability are affected by solubility and stability which may result in decreased absorption of the nutrient in the body. This problem is solved by using nanotechnology. To increase the bioavailability of nutrients susceptible to degradation novel nanoencapsulation methods have been developed. This method offers an effective route to maintain nutritional value, stability, and controlled release of bioactive components (Srinivas et al., 2010; Sankaria et al., 2012). Nanoparticles may alter the absorption, digestion, metabolism, and excretion in the body due to its severa beneficial properties such as higher exposure of per unit mass, small size, large surface area, different route of exposure, different distribution to tissues because of their different size, surface coating or particle charge (Srinivas et al., 2010).

\section{Probiotic}

In recent year's nanotechnology play a vital role in the delivery of probiotics that protect our body from diseases and provide nourishment through a biological process. Nanoencapsulation of beneficial microorganisms such as L. salivations, L. acidophilus, and Saccharomyces spp. Thermophiles and Bifidobacterium confer health benefit effects by improving digestion of food, increase energy storage, fermentation of sugar, preventing the formation of tumours, stimulating the release of antibiotics, and inhibit the development of the pathogenic condition. Probiotic bacteria coated with nanoparticles are resistant to degradation by gastric acid. Encapsulated probiotics are beneficial to human as their functions and properties are not affected during processing and they can reach target locations in the body without degradation (Chung et al., 2010) A protective coating for lactic acid bacteria have been developed which is resistant to heat, acid, and bile and has increased stability (Sankaria et al., 2012).

\section{Antioxidant}

Zhang et al., (2014) developed the process of encapsulation of anthocyanin, a major group of water-soluble plant pigment. Anthocyanin is a potentia antioxidant, anticancer, anti-inflammatory, antidiabetic, and antiaging and cardioprotective agent. But the main problems are oxonium ions present in anthocyanin makes it vulnerable to nucleophilic attack by various antioxidants and difficulties in the storage of anthocyanin due to its instability by heat, oxygen, light, and some enzymes. To avoid these major problems Cyanidin 3-O-glucoside (C3G) molecules are encapsulated in the inner cavity of apo recombinant soybean seed, as a result, the thermal stability of anthocyanin is improved. The study conducted by Yang et al., (2015) describe that encapsulation of hydrophobic rutin molecule is possible. Through this method, the thermal and UV radiation stability of rutin trapped within ferritin is increased. The antioxidant activity of FRNs was also retained as compared to free rutin.

\section{Nutraceutical}

The delivery of lipid-soluble bioactive compounds is done by using nano emulsion which can be prepared by natural food ingredients and designed in such a way that it can enhance water dispersion and bioavailability of food ingredients (Singh $\boldsymbol{e}$ al., 2018). Nanoparticles improve the bioavailability of nutraceutical compounds due to their subcellular size beneficial for higher drug bioavailability. To improve the bioavailability of nutraceutical compounds, the food industry trying to increase the circulation time of nanocarriers in the GI tract, by surface coating with a protein. $\mathrm{SiO} 2$ nanomaterials are used in food to improve the fragrance or flavor of food products. The major life-supportive bioactive compound such as lipids, proteins, fat, and carbohydrate are sensitive to high acidic environments and enzymatic activity of the stomach. Nanoencapsulation of this compound protect them from any adverse condition and helps to assimilate easily in food products in 
terms of improved digestibility of those bioactive compounds, which is hard to achieve in case of non- capsulated form because of their low water solubility. Polymeric nanoparticles are effective for the encapsulation of bioactive compounds such as flavonoids and vitamins to protect and transport them to the target cells (Chen et al., 2006).

\section{CONCLUSION}

In recent few decades, nano protein and nanotechnology give a promising effect in the food industry. It is used in food processing and food packaging technology. Nano proteins preserve food and enhance shelf life which ensures the health aspect of the consumer. It can retain the color, flavor, texture, and appearance of the bioactive compound as a result it is considered an effective vehicle system to deliver micronutrients, antioxidants, nutraceuticals to the target tissue. The methods of formation of nano protein from different sources are under investigation. The use of nano protein in various aspects is increased day by day.

Conflict of interest: The authors are unanimous in publishing this paper. There is also nobody to contradict this manuscript.

Acknowledgments: The authors would like to express their deepest gratitude to the West Bengal State University, Barasat for giving permission to conduct this study. We are also indebted to the teachers of Dept. of Food and Nutrition, WBSU, Barasat for their kind assistance during review.

\section{REFERENCES}

Arora, A., \& Padua, G.W. (2010). Review: Nanocomposite in food packaging. Journal of Food science, 75(1), 43-49. https://doi.org/10.1111?j.17503841.2009.01456.x

Abdou, E.S., Osheba, A.S., \& Sorour, M.A. (2012). Effect of chitosan and chitosan-nanoparticles as an active coating on microbiological characteristics of fish fingers. International Journal of Applied Science and Technology, 2, 158169

Anderson, T.J., \& Lamsal, P.B. (2011). REVIEW: Zein Extraction from Corn, Corn Products, and Coproducts and Modifications for Various Application. Cerea Chemistry, 88, 159-173. https://doi.org/10.1094/CCHEM-06-10-0091

Burcu, C., Burcu, O., Nicoleta, S., \& Harsa, S. (2014). Nanoencapsulation biologically active peptides whey protein. Journal of Nutritional Health \& Food Science, 5(6), 062001. https://doi.org/10.15226/jnhfs.2014.00126.

Brandenbur, A., Weller, C.L, \& Testin, R.F. (1993). Edible films and coating from soya protein. Journal of food science, 58(5),1365-2621. https://doi.org/10.1111/j.1365-2621.1993.tb06120.x

Bajpai, V.K., Kamle, M., Shukla, S., Mahato, D.K., Chandra, P., \& Hwang, S.K. (2018). Prospects of using nanotechnology for food preservation, safety, and security. Journal of Food and Drug Analysis, 26(4), 1201-12014. https://doi.org/10.1016/j.jfda.2018.06.011

Chaudhury, Q., Scotter, M., Blackburn, J., Ross, B., Boxail, A., Castle, L., Aitken, R., \& Watkins, R. (2008). Application and implication of nanotechnology for the food sector. Food Additives and Contaminants, 25(3), 241-258. https://doi.org/10.1080/02652030701744538

Chen, L., Remondetto, G.E., \& Subriad, M. (2006). Food protein-based material as nutraceutical delivery systems. Journal of Food Science \& Technology, 17 (5), 272-283. https://doi.org/10.1016/j.tifs.2005.12.011

Chung, M.J., Kim, D.M., \& Lee, G.S.A. (2010). Method of preparing triple coating lactic acid bacteria and nanoparticle coating lactic acid bacteria. PAT - US2010278975.

Cedervall T., Lynch, I., Lindman, S., Berggard, T., \& Thulin, E. (2007) Understanding the nanoparticle-protein corona using methods to quantify exchange rates and affinities of proteins for nanoparticle. Proceedings of National Academi of Sciences of the United State Of America, 104 (7), 2050-2055. https://doi.org/10.1073/pnas.0608582104

Cedervall T., Lynch, I., Foy, M., Berggard, T., Donnelly, S.C., Cagney, G., Linse, S., \& Dawson, K.A. (2007). Detailed identification of plasma proteins adsorbed on copolymer nanoparticles. Journal of german chemical society, 46(30), 5754 https://doi.org/10.1002/anie.200700465

Cheng, D., Yong, X., Zhu, T., Qiu, Y., \& Jun, W. (2016). Synthesis of protein nanoparticle for drug delivery. European Journal of Biomedical Research. 2(2), 7 11. http://dx.doi.org/10.18088/ejbmr.2.2.2016.pp7-11

Cabuk, B., Okuklu, B., Stanciuc, N., \& Harsa, S.T. (2014). Nanoencapsulation of Biologically Active Peptides from Whey Proteins. Journal of Nutritional Health \& Food Science, 2(3), 1-4. https://doi.org/10.15226/jnhfs.2014.00126

Chakraborty, A., \& Jana, N.R. (2017). Vitamin C-conjugated nanoparticle protects cells from oxidative stress at low doses but induces oxidative stress and cell death at high doses. ACS Applied Materials and Interfaces, 9(48), 41807-41817. https://doi.org/10.1021/acsami.7b16055

Dimitrijevic, M., Karabasila, N., Boskovica, M., Teodorovica, V., Vasileva, D. Djordjevic, V., \& Cobanovic, K. (2015). The safety aspect of nanotechnology application in food packaging. Procedia Food Science, 5(2015), 57-60. https://doi.org/10.1016/j.profoo.2015.09.015

Dekkers, S., Krystek, P., Peters, R.J., Lankveld, P.K., Bokkers, B. G., \& Arentzen,V.H. (2011). Presence and risks of nanosilica in food products. Nanotoxicology,

$5(3)$

$393-405$

https://doi.org/10.3109/17435390.2010.519836

DeFrates, K., Markiewicz, T., Gallo, P., Rack, A.,Weyhmiller, A., Jarmusik, B., \& $\mathrm{Hu}, \mathrm{X}$. (2018). Protein Polymer-Based Nanoparticles: Fabrication and Medical Applications. International Journal of Molecular Science, 19(6), (1717).https://doi.org/10.3390/ijms19061717.

Gatoo, M.A., Naseem, S., Arfat, M.Y., Dar, M.A., Qasim, K., \& Zubair, S. (2014). Physicochemical Properties of Nanomaterial: Implication in Associated Toxic Manifestations. Biomed Research International, 2014, 1-8. https://doi.org/10.1155/2014/498420 .

Guo, Y., Zhang, X., Hao, W., Xie, Y., Chen, L., Zhu, B., Li, Z., \& Feng, X (2018) Nano-bacterial cellulose/soy protein isolate complex gel as fat substitutes in ice cream model. Carbohydrate Polymers, 198, 620-630 https://doi.org/10.1016/j.carbpol.2018.06.078

Guo, Y., Harris, P., Kaur, A., Pastrana, L., \& Jauregi, P. (2017). Characterization of b-lactoglobulin nanoparticles and their binding to caffeine. Food Hydrocolloids, 71, 85-93. https://doi.org/10.1016/j.foodhyd.2017.04.027

Gupta, A., Eral, B.H., Hatton, A.T., \& Doyle, S.P. (2016). Nanoemulsions formation, properties, and applications. Royal Society of Chemistry, 2016, 12, 2826-2841. https://doi.org/10.1039/c5sm02958a

Ghasemi, S., Jafri, S.M., Assadpour, E., \& Khomeiri, M. (2017). Production of pectin-whey protein nano-complexes as carriers of orange peel oil. Carbohydrate polymer, 177 (2017), 369-37. https://doi.org/10.1016/j.carbpol.2017.09.009

He, W., Tan, Y., Tan, Z., Chen, L., \& Wu, W. (2011). Food protein-stabilized nanoemulsions as potential delivery systems for poorly water-soluble drugs: preparation, in vitro characterization, and pharmacokinetics in rats; International Journal of Nanomedicine, 2011(6), 521-533. https://doi.org/10.2147/IJN.S17282 Jaiswal, M., Dudhe, R., \& Sharma, P.K. (2015). Nanoemulsion: an advanced mode of drug delivery system. Biotechnology, 5, 123-127. https://doi.org/10.1007/s13205-014-0214-0 .

Jampilek, J., Kos, J., \& Kralova, K. (2019). Potential of Nanomaterial Applications in Dietary Supplements and Foods for Special Medical Purposes. Nanomaterials (Basel), 9(2), 1-42. https://doi.org/10.3390/nano9020296

Jiang, J., Oberdorster, G., Elder, A., Gelein, R., Mercer, P., \& Biswas,P.(2008) Does Nanoparticle Activity Depend Upon Size and Crystal Phase? Nanotoxicology, 2(1), 33-42. https://doi.org/10.1080/17435390701882478

Khan, I., Saeed, K. \& Khan, I. (2017). Nanoparticles: Properties, application, and toxicities. Arabian journal of chemistry. 12(7), 908-931. https://doi.org/10.1016/j.arabjc.2017.05.011

Kinsella, J.E., Whitehead, D.M., \& Brady, J. (1989). Milk proteins: Possible relationships of structure and function. Developments in Dairy Chemistry, 4, 131172

Kulkarni, A.S., Ghugre, P.S., \& Udipi, S.A. (2016). 15 - Applications of nanotechnology in nutrition: potential and safety issues. Novel Approaches of Nanotechnology in Food, 1, 509-554. https://doi.org//10.1016/B978-0-12-804308$\underline{0.00015-7}$

Liu, Q., Huang, H., Chen, H., Lin, J., \& Wang, Q. (2019). Food-Grade Nanoemulsions: Preparation, Stability, and Application in Encapsulation of Bioactive Compounds Molecules, 24(23) 37.https://doi.org/10.3390/molecules24234242

Liu, F., \& Tang, C. H, (2013). Soya proteins nanoparticles at Pickering stabilizers for oil in water emulsions. Journal of agriculture and food chemistry, 61, 37, 88888898. https://doi.org//10.1021/jf401859y

Lobo, V., Patil, A., Phatak, A., \& Chandra, N. (2010). Free radicals, antioxidants, and functional foods: Impact on human health. Pharmacognosy reviews. 4(8), 118 126. https://doi.org/10.4103/0973-7847.70902

Liu, Y., Ai, K., Ji, X., Askhatova, D., Du, R., Lu, L., \& Shi, J. (2017). Comprehensive insights into the multi-antioxidative mechanisms of melanin nanoparticles and their application to protect the brain from injury in ischemic stroke. Journal of American Chemical Society. 139(2), 856-862. https://doi.org/10.1021/jacs.6b11013

Mohan, A., Rajendra, S.R.C.K., \& Laurent, B. (2015). Encapsulation of food protein hydrolysate and peptide. RSC Advance, 5, 79270-79278. https://doi.org/10.1039/C5RA13419F

Meghani, N., Dave, S., \& Kumar, A. (2019). Nanofood and its Application - A Review. BAOJ Nanotech, 5(1), 1-16.

Martins, J.T., Bourbon, A.L., Pinheiro, A.C., Fasolin, L.H., \& Vicente, A.A (2018). Food-Based Structures for Food Applications: From Macro to Nanoscale. Frontiers in Sustainable Food Systems. 2 (77), 1-18. https://doi.org/10.3389/fsufs.2018.00077

Nakagawa, K. (2014). Nano- and micro-encapsulation of flavor in food systems, in Nano- and Microencapsulation for Foods. Chap. 10, ed. H.-S. Kwak (Oxford John Wiley \& Sons), 249-272. https://doi.org//10.1002/9781118292327.ch10 Peles, Z., Binderman, I., Berdicevsky, I., \& Zilberman, M. (2013). Soy protein film from wound healing application. Journal of Tissue Engineering and Regenerative Medicine,7(5) 401-412. https://doi.org/10.1002/term.536

Srinivas, P.R, Philbert, M., Vu, T.Q., Huang, Q., Kokini, J.L., Saos, E., \& Ross, A, S. (2010). Nanotechnology research: Application in nutrition science. Journal of Nutrition. 140, 119-124. https://doi.org/10.3945/jn.109.115048 
Singh, T., Shukla, S., Kumar, P., Wahla, V. \& Bajpai V.K. (2017). Application of nanotechnology in food science: perception and overview. Frontiers in microbiology, 8(1501), 1-8.https://doi.org/10.3389/fmicb.2017.01501

Sharma, C., Dhiman, R., Rokana, R., \& Panwar, H. (2017). Nanotechnology: an untapped resource for food packaging. Frontiers in Microbiology, 8(1735),1-22. https://doi.org/10.3389/fmicb.2017.01735

Sankaria, S., Ahn, S.H., Khare, V. (2012). Nanotechnology and its impact on food and nutrition: a review. Recent Patents on Food, Nutrition \& Agriculture.4(1), 818. https://doi.org/10.2174/2212798411204010008

Saptarshi, S.R., Duschl, A., Lopata, A.L. (2013). Interaction of nanoparticles with proteins: relation to bio-reactivity of the nanoparticle. Journal of Nanobiotechnology,11(26),

http://www.jnanobiotechnology.com/content/11/1/26

Schmidt, D, G., \& Markwijk, B.W. (1993). Enzymatic hydrolysis of whey proteins. Influence of heat-treatment of $\alpha$-lactalbumin and $\beta$-lactoglobulin on their proteolysis by pepsin and papain. Netherland Milk Dairy Journal, 47, 15-22.

Singh,P,K., Jairath,G., \& Ahlawat,S,S.(2016). Nanotechnology: a future tool to improve quality and safety in the meat industry. Journal Food Science and Technology, 53(4), 1739-1749. https://doi.org/10.1007/s13197-015-2090-y

Srinivas, P.R, Philbert, M., Vu, T.Q., Huang, Q., Kokini, J.L., \& Saos, E. (2010) Nanotechnology research: Application in nutrition science. Journal of nutrition, 140, 119-124. https://doi.org/10.3945/jn.109.115048

Shpigelman, A., Cohen, Y., \& Livney, Y.D. (2012). Thermally-induced blactoglobulin-EGCG nano vehicles: loading, stability, sensory and digestive release study. Food Hydrocolloids, 29, 57-67. https://doi.org/10.1016/j.foodhyd.2012.01.016

Sengupta, S., Bhattacharyya, D.K., Goswami, R., Bhowal, J. (2019). Emulsions stabilized by soy protein nanoparticles as potential functional non-dairy yogurts. Journal of the Science of Food and Agriculture, 99 (13), 58085818.https://doi.org/10.1002/jsfa.9851

Sengupta, S., Bhattacharyya, D.K., \& Bhowal, J.(2018). Improved Quality Attributes in Soy Yogurts Prepared From DAG Enriched Edible Oils and Edible Deoiled Soy Flour. European Journal of Lipid Science and Technology, 120(8), 1 10. https://doi.org/10.1002/ejlt.201800033

Sengupta, S., Koley, H., Dutta, S., \& Bhowal, J. (2019a). Hepatoprotective effects of synbiotic soy yogurt on mice fed on high cholesterol diet. Nutrition,63-64, 3644. https://doi.org/10.1016/j.nut.2019.01.009

Sengupta, S., Koley, H., Dutta, S., \& Bhowal, J. (2019b). Antioxidant and hypocholesterolemic properties of functional soy yogurts fortified with $\omega-3$ and $\omega$ 6 polyunsaturated fatty acids in Balb/c mice. European Journal of Lipid Science and Technology, 1800397, 1-12. https://doi.org/10.1002/ejlt.201800397

Tansaz, S. (2016). Biomedical application of soya protein. Journal of biomedical natural research, 104(2), 553-569. https://doi.org/10.1002/jbm.a.35569

Teng, Z., Luo, Y., \& Wang, Q. (2012). Nanoparticles Synthesized from Soy Protein: Preparation, Characterization, and Application for Nutraceutical Encapsulation. Journal of Agriculture and Food Chemistry, 60(10), 2712-2720. https://doi.org/10.1021/jf205238x

Yusof, F.,\& Ismail, N.A.S. (2015). Antioxidants effects of platinum nanoparticles: A potential alternative treatment to lung diseases. Journal of Applied. Pharmaceutical Science, 5, 140-145. https://doi.org/10.7324/JAPS.2015.50722

Yalcmoz, S., \& Ercelebi, E. (2018). Potential application of nanoemulsion in the food system. Materials Research Express, 5 , 062001.https://doi.org/10.1088/2053-1591/aac7ee

Yang, R., Zhou, Z., Sun, G., Gao, Y., Xu, J., Strappe, P. \& Ding, X. (2015). Synthesis of homogeneous protein-stabilized rutin nanodispersions by the reversible assembly of soybean (Glycine max) seed ferritin. RSC Advances. 5 , 31533-31540. https://doi.org/10.1039/C5RA03542B

Yin, B., Deng, W., Xu, K., Huang, L., \& Yao, P. (2012). Stable nano-sized emulsions produced from soy protein and soy polysaccharide complexes. Journal of Colloid and Interface Science. 380, 51-59. https://doi.org/10.1016/j.jcis.2012.04.075

Yildiz, G., Andrade, J., Engeseth, E.N, \& Feng, H. (2017). Functionalizing soy protein nano-aggregates with $\mathrm{pH}$ shifting and nano-thermo-sonication. Journal of $\begin{array}{llrl}\text { colloid and interface science, } & 505, & 836-846 .\end{array}$ https://doi.org/10.1016/j.jcis.2017.06.088

Yi, J., Lam, T. I., Yokoyama, W., Cheng, L.W., \& Zhong, F. (2015). Beta-carotene encapsulated in food protein nanoparticles reduces peroxyl radical oxidation in Caco-2 cells. Food Hydrocolloids. 43, 31-40. https://doi.org/10.1016/j.foodhyd.2014.04.028

Zhang, T., Lv, C., Chen, L., Bai, G., Zhao, G., \& Xu, C. (2014). Encapsulation of anthocyanin molecules within a ferritin nanocage increases their stability and cell uptake efficiency. Food Research International. 62, 183-192. https://doi.org/10.1016/j.foodres.2014.02.041 .

Zhao, C., Shen, X., \& Guo, M. (2018). Stability of Lutein Encapsulated Whey Protein Nano-Emulsion During Storage. PLoS ONE 13(2),1-10. https://doi.org/10.1371/journal.pone.0192511 